\title{
UV DERIVATIVE SPECTROPHOTOMETRIC METHOD FOR DETERMINATION OF ESTRADIOL VALERATE IN
} TABLETS

\author{
Andreas S. L. Mendez* \\ Curso de Farmácia, Universidade Federal do Pampa, BR 472 - km 592, 97500-970 Uruguaiana - RS, Brasil \\ Lislaine Deconto \\ Curso de Farmácia, Universidade Regional Integrada, Av. Sete de Setembro, 1621, 99700-000 Erechim - RS, Brasil \\ Cássia V. Garcia \\ Faculdade de Farmácia, Universidade Federal do Rio Grande do Sul, Av. Ipiranga, 2752, 90610-000 Porto Alegre - RS, Brasil
}

Recebido em 24/8/09; aceito em 12/11/09; publicado na web em 12/3/10

\begin{abstract}
A derivative UV spectrophotometric method for determination of estradiol valerate in tablets was validated. The parameters specificity, linearity, precision, accuracy, limit of detection and limit of quantitation were studied according to validation guidelines. The first-order derivative spectra were obtained at $\mathrm{N}=5, \Delta \lambda=4.0 \mathrm{~nm}$, and determinations were made at $270 \mathrm{~nm}$. The method showed specificity and linearity in the concentration range of 0.20 to $0.40 \mathrm{mg} \mathrm{mL}^{-1}$. The intra and interday precision data demonstrated the method has good reproducibility. Accuracy was also evaluated and results were satisfactory. The proposed method was successfully applied to a pharmaceutical formulation.
\end{abstract}

Keywords: estradiol valerate; UV derivative spectrophotometric method; method validation.

\section{INTRODUCTION}

Estradiol valerate (Figure 1), estra-1,3,5(10)-triene-3,17diol(17ß)-17-pentanoate, is one of the most common sources for free estradiol in hormone replacement therapy. ${ }^{1}$ This therapy is considered to be effective for climacteric symptoms, such as hot flushes and sleep problems, and is helpful in the prevention of osteoporosis and atrophic changes in the genital tract. ${ }^{2-4}$ Many pharmaceuticals containing estradiol are available in the market, mainly in association with progestagen. This association is recommended to avoid some risks such as incidence of endometrial hyperplasia and endometrial carcinoma in non-hysterectomised postmenopausal women. ${ }^{5}$

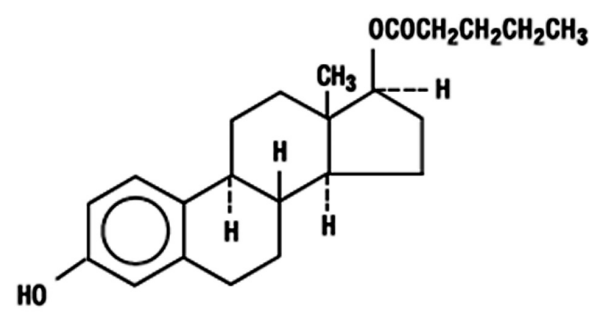

Figure 1. Chemical structure of estradiol valerate

The literature survey reveals several publications related to estradiol valerate determination. The most of the methods describes the analysis in formulations containing the drug in association with other hormones, such as megestrol acetate by spectrophotometry, testosterone enanthate by HPLC and medroxyprogesterone acetate by HPLC. ${ }^{6-8}$ Recently, a derivative spectrophotometry method was proposed for the simultaneous quantitative analysis of a binary mixture containing estradiol valerate and cyproterone acetate in commercial pharmaceutical preparations. ${ }^{9}$ The determination was carried out by

*e-mail: andreaslmendez@yahoo.com.br using ratio spectra derivative spectrophotometry and two chemometric methods. In the method of Segall et al., ${ }^{8}$ the chromatographic analysis of the combination estrogen-gestagen had a good performance, including the detection of degradation products during selectivity parameter determination.

Several methods are also applied to detect and quantify the $\beta$ estradiol (free form) and its metabolites in biological fluids, such as plasma and urine by HPLC. ${ }^{10-12}$ Some recent publications describe the determination of $\beta$-estradiol and its derivatives like ethynylestradiol, estradiol 3-methyl ether, and estradiol 17-acetate in pharmaceutical formulation. ${ }^{13-16}$ In the study of Havlíková et al.,${ }^{16}$ the stability of $\beta$ estradiol in topic gel was evaluated, and the HPLC method developed presented a good performance to separate the degradation products, allowing the reliable quantitation of the drug.

As cited previously, the association of the estradiol valerate (or free form) with other hormone is very common, resulting in many works describing about the development of methods for simultaneous determination. For commercial samples containing estradiol valerate alone, few methods are listed in the recent literature. A fluorometric determination of this drug in injectables was proposed. ${ }^{17}$ Nowadays, the HPLC method found in the United States Pharmacopoeia is the main reference, but there is no monograph of estradiol valerate in tablets. ${ }^{18}$ The monograph of estradiol valerate in bulk and injection details a quantitation by HPLC which uses an internal standard prepared with tetrahydrofuran, a mobile phase containing ammonium nitrate, and UV detection. For $\beta$-estradiol, there are methods applied to bulk, tablets, cream, and other pharmaceutical dosage forms.

The absence of other techniques to determine estradiol valerate when alone in commercial formulations led to a study to provide a simple analytical alternative to quality control of this drug. Thus, in the present work we present a first-order spectrophotometric method to determine estradiol valerate in tablets. The method was developed and validated following the validation guidelines, ${ }^{18,19}$ and the parameters specificity, linearity, precision, accuracy, and detection and quantitation limits were determined. 


\section{EXPERIMENTAL}

\section{Chemicals}

Estradiol valerate reference standard was kindly supplied by DEG (São Paulo, Brazil). The tablets $\left(\right.$ Merimono $\left.^{\circledR}\right)$, containing $1 \mathrm{mg}$ of estradiol valerate, were obtained commercially. The excipients of the pharmaceutical formulation were lactose, corn starch, povidone, talc, magnesium stearate, hydroxypropyl cellulose, and laca FD \& $\mathrm{C}$ blue as coloring agent. All of them were obtained from different local distributors. Methanol analytical grade obtained from Merck (Darmstadt, Germany) was used to prepare all solutions for analysis.

\section{Apparatus and conditions}

An Agilent UV-VIS 8453E double-beam spectrophotometer with $1 \mathrm{~cm}$ quartz cells and data processing capacity was used. The firstorder derivative spectra were obtained over the $200-400 \mathrm{~nm}$ range and $\mathrm{N}=5, \Delta \lambda=4.0 \mathrm{~nm}$. The determinations were made at $270 \mathrm{~nm}\left({ }^{1} \mathrm{D}_{270}\right)$.

\section{Validation protocol}

\section{Specificity}

The specificity of the method was evaluated through the analysis of a placebo solution, which was prepared with the excipients of the pharmaceutical formulation in their usual concentration. ${ }^{20}$

\section{Linearity}

Aliquots of a $1.0 \mathrm{mg} \mathrm{mL}^{-1}$ solution of estradiol valerate reference standard were transferred to volumetric flasks to obtain the final concentrations of $0.20,0.25,0.30,0.35$ and $0.40 \mathrm{mg} \mathrm{mL}^{-1}$. Each solution was prepared in triplicate. The linearity was evaluated by linear regression analysis, which was calculated by the least square regression method, and by ANOVA.

\section{Precision}

Twenty tablets were weighed and powdered. A quantity equivalent to $7.50 \mathrm{mg}$ of estradiol valerate was weighed, transferred to $25.0 \mathrm{~mL}$ volumetric flask containing methanol and shaken for $15 \mathrm{~min}$ in a ultrasonic bath. The volume was completed with the same solvent. The solution was filtered and used in the analysis at a final concentration of $0.30 \mathrm{mg} \mathrm{mL}^{-1}$. New solutions were prepared in 3 days for interday precision evaluation.

\section{Accuracy}

The accuracy of the method was evaluated through the recovery test. From a estradiol valerate standard solution of $5.0 \mathrm{mg} \mathrm{mL}^{-1}$, aliquots of 1.5, 2.0, and $2.5 \mathrm{~mL}$ were taken and transferred to $50 \mathrm{~mL}$ volumetric flasks containing $25 \mathrm{~mL}$ of the sample solution at $0.2 \mathrm{mg} \mathrm{mL}^{-1}$ (prepared according the same procedure cited for precision). The volume was completed with methanol, obtaining the final concentrations of 0.25 , 0.30 and $0.35 \mathrm{mg} \mathrm{mL}^{-1}$, respectively. Each solution was done in triplicate.

\section{RESULTS AND DISCUSSION}

The development of this method started with preliminary tests applied to establish the main parameters of the assay, the solvent and the concentration of analysis. Different solvents were tested, such as water, methanol, and ethanol. Methanol was selected since it had a great capability to dissolve the drug, mainly during extraction from tablets. Although water is the better solvent considering toxicological risks and the absence of demanding residue storage, it did not present a good potential to dissolve the drug in conditions assayed.
Testing these conditions, it was verified the low absorbance of estradiol valerate in a UV range. Thus, final concentrations of analysis solutions were increased. The same situation was published by Segall et al.,${ }^{8}$ which worked with the HPLC analysis of estradiol valerate in a binary mixture at a concentration of $0.40 \mathrm{mg} \mathrm{mL}^{-1}$. Several tests were done to find the better condition in this parameter.

In order to choose the optimal condition for the derivative method, different orders were tested, as well as different $\mathrm{N}$ (experimental points as smoothing function). The first-order demonstrated to be adequate and $\mathrm{N}=5$ the condition that allowed high amplitude and good spectra profile. Values of $\mathrm{N}$ higher than 5 produced noisy spectra and distorted the spectral resolution. The derivative wavelength difference $(\Delta \lambda)$ originated from this combination was $4.0 \mathrm{~nm}$, according to the equipment used.

The UV spectra of estradiol valerate reference standard, sample solution and placebo solution are represented in Figure 2. It is possible to observe a peak between 270 and $290 \mathrm{~nm}$ range, and the interference of the placebo solution at this range. In this case, the zero order UV spectrophotometric method cannot be used to analyze the pharmaceutical dosage form without another tool. Observing the firstorder spectrum Figure 3, the analysis did not suffer any interference of the placebo at the determination wavelength $(270 \mathrm{~nm})$, allowing a reliable determination. According to Ojeda and Rojas, compared with conventional spectrophotometric determinations, derivative spectrophotometry has proved to be of great value in eliminating the interference from excipients and co-formulated drugs. ${ }^{21}$

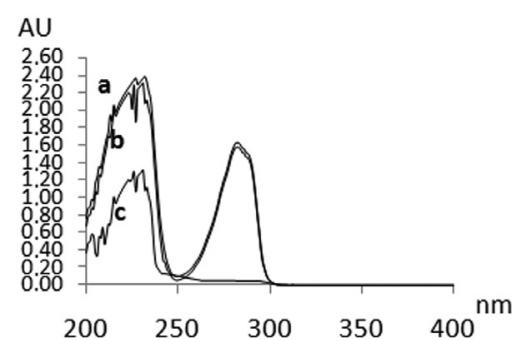

Figure 2. UV spectra of estradiol valerate reference standard (a), sample solution (b) and placebo (c), in methanol at concentration of $0.30 \mathrm{mg} \mathrm{mL}^{-1}$

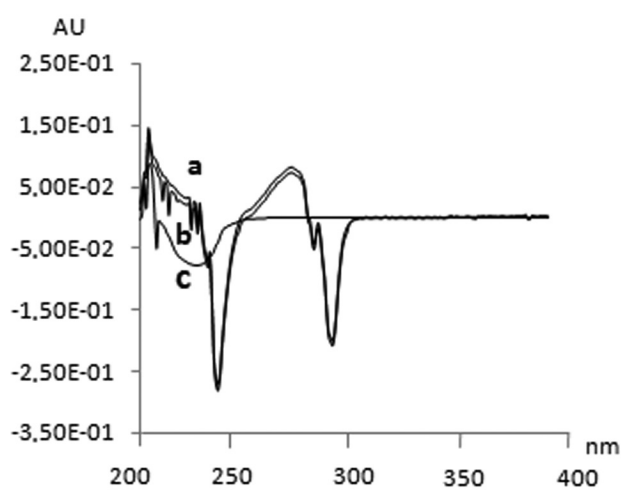

Figure 3. First-order derivative spectra of estradiol valerate reference standard (a), sample solution (b) and placebo (c), in methanol at concentration of $0.30 \mathrm{mg} \mathrm{mL}^{-1} . N=5, \Delta \lambda=4.0 \mathrm{~nm}$

The results from linearity (regression equation, correlation coefficient) are demonstrated in Table 1. The data was validated by means of analysis of variance (ANOVA), which demonstrated significative linear regression and nonsignificant linearity deviation $(\mathrm{P}<0.05)$. From this data [standard deviation (SD) of response and slope curve $(\mathrm{S})$ ], it was possible to calculate the detection and quantitation limits. ${ }^{18,19}$ The results found were $\mathrm{LOD}=0.017 \mathrm{mg} \mathrm{mL}^{-1}$ and $\mathrm{LOQ}=0.052 \mathrm{mg} \mathrm{mL}^{-1}$. 
Table 1. Results of standard curve of first-order derivative spectrophotometric method for estradiol valerate determination

\begin{tabular}{lc}
\hline Feature & ${ }^{1} \mathrm{D}_{270}$ \\
\hline Regression equation & $\mathrm{y}=0.2556 \mathrm{x}+0.0022$ \\
Correlation coefficient $(\mathrm{r})$ & 0.9948 \\
Linear range $\left(\mathrm{mg} \mathrm{mL}^{-1}\right)$ & $0.20-0.40$ \\
\hline
\end{tabular}

The determinations of commercial samples showed good reproducibility, with $\mathrm{RSD}=0.16$ for ${ }^{1} \mathrm{D}_{270}$, in 3 days. The results obtained each day are presented in Table 2. All values for relative standard deviation are below 2.0. The mean amount of estradiol valerate was $101.15 \%$. The evaluation of accuracy of the method, made through the recovery test, showed it is accurate, with mean recovery of $99.94 \%$ for ${ }^{1} \mathrm{D}_{270}$ (Table 3). These parameters are important to be verified and allow knowing the performance of the assay, mainly considering the objectives of pharmaceutical quality control.

Table 2. Results obtained from determinations of commercial samples of estradiol valerate by first-order derivative spectrophotometric method in precision assay

\begin{tabular}{|c|c|c|c|c|c|}
\hline \multirow[b]{2}{*}{ Data } & \multicolumn{4}{|c|}{ Amount (\%) } & \multirow[b]{2}{*}{ RSD interdays } \\
\hline & First day ${ }^{a}$ & Second day ${ }^{\mathrm{a}}$ & Third day ${ }^{\mathrm{a}}$ & Mean $(\%)$ & \\
\hline Results & 101.35 & 100.77 & 101.34 & 101.15 & 0.32 \\
\hline RSD & 0.57 & 0.26 & 0.68 & & \\
\hline
\end{tabular}

${ }^{\text {a }}$ mean of six determinations.

Table 3. Results obtained from recovery test for determination of estradiol valerate by first-order derivative spectrophotometric method

\begin{tabular}{lcccc}
\hline \multirow{2}{*}{ Data } & \multicolumn{4}{c}{ Concentration $\left(\mathrm{mg} \mathrm{mL}^{-1}\right)$} \\
\multirow{3}{*}{ Results } & 0.15 & 0.1498 & 99.88 & \\
& 0.20 & 0.1989 & 99.46 & 99.94 \\
& 0.25 & 0.2512 & 100.50 & \\
\hline
\end{tabular}

aeach value is mean of three determinations

Since the chromatographic methods are more expensive, time consuming, and need more steps, the proposed spectrophotometric method is adequate for routine analysis as an alternative technique, simple and cheap. Beyond it, this technique offers an alternative approach to the enhancement of sensitivity and specificity in mixture analysis. ${ }^{21}$ Recently, a revision about the derivative UV/visible spectrophotometry was published, describing the advantages of the method, including the application to pharmaceuticals. ${ }^{22}$ Another important application could be in dissolution studies, which need rapid and accurate results.

It is important to conduct the development of this kind of method with precaution and respect the issues present in international guidelines in order to avoid errors. In this work, problems concerning reproducibility were not found, but the analyst has to give attention to this matter. According to Karpinska, the main disadvantage of the derivative method is the low reproducibility. ${ }^{23}$ Besides, it is necessary have caution with the specificity, mainly for steroidal drugs, with the chemical structures have similar groups that can interfere with the analysis. This point justifies the importance of the development and validation of methods following the principles described by the guidelines.

\section{CONCLUSIONS}

The results of validation showed that the analytical procedure presents a good performance to determine estradiol valerate in pharmaceutical dosage form. The first-order derivative spectrophotometric method demonstrated to be simple, rapid, precise, accurate and specific, and can be used for the drug analysis in routine quality control.

\section{REFERENCES}

1. Seidman, D. S.; Itsekson A.; Alesker, M.; Zolti, M.; Carp, H.; Wolman, I.; Fert. Steril. 2009, 91, 1510.

2. Bukulmez, O.; Al, A.; Gurdal, H.; Yarali, H.; Ulug, B.; Gurgan, T.; Fertil. Steril. 2001, 75, 737.

3. Wihlbäcka, A.; Nyberg, S.; Bäckström, T.; Bixo, M.; SundströmPoromaa, I.; Psychoneuroendocrinology 2005, 30, 38.

4. Lee, B. S.; Kang, B. M.; Yoon, B. K.; Choi, H.; Park, H. M.; Kim, J. G.; Maturitas 2007, 57, 361.

5. Alwers, R.; Urdinola, J.; Onatra, W.; Sánchez, F.; Posso, H.; Maturitas 1999, 32, 41.

6. Hong, Z.; Lu, B.; Wang, C.; Hиа Xi Yi Ke Da Хие Хие Bao 2001, 22, 87.

7. Carignan, G.; Lodge, B. A.; Skakum, W.; J. Chromatogr. 1984, 301, 292.

8. Segall, A.; Hormaechea, F.; Vitale, M.; Perez, V.; Pizzorno, M. T.; J. Pharm. Biomed. Anal. 1999, 19, 803.

9. Dinç, E.; Yücesoy, C.; Palabıyık, I. M.; Özgür, Ü.; Onur, F.; J. Pharm. Biomed. Anal. 2003, 32, 539.

10. Yamada, H.; Yoshizawa, K.; Hayase, T.; J. Chromatogr., B 2002, 775, 209.

11. Guo, T.; Gu, J.; Soldin, O. P.; Singh, R. J.; Soldin, S. J.; Clin. Biochem. 2008, 41,736

12. Gadzała-Kopciuch, R.; Ričanyová, J.; Buszewski, B.; J. Chromatogr., B 2009, 877, 1177.

13. Gatti, R.; Gioia, M. G.; Di Pietra, A. M.; Cavrini, V.; J. Pharm. Biomed. Anal. 1998, 18, 187

14. Salci, B.; Biryol, I.; J. Pharm. Biomed. Anal. 2002, 28, 753.

15. Nováková, L.; Solich, P.; Matysová, L.; Sícha, J.; Anal. Bioanal. Chem. 2004, 379, 781 .

16. Havlíková, L.; Nováková, L.; Matysová, L.; Sícha, J.; Solich, P.; J. Chromatogr., A 2006, 1119, 216.

17. James, T.; J. Assoc. Off. Anal. Chem. 1973, 56, 86.

18. USP; The United States Pharmacopoeia, $31^{\text {rd }}$ revision, The United States Pharmacopoeial Convention: Rockville, 2008.

19. ICH; International Conference on Harmonization of Technical Requeriments for Registration of Pharmaceuticals for Human Use, Q2B(R1): Guideline on Validation of Analytical Procedure-Methodology, 2005.

20. Kibbe, A. H.; Handbook of pharmaceutical excipients, $3^{\text {rd }}$ ed., American Pharmaceutical Association: Washington, 2000.

21. Ojeda, C.; Rojas, F.; Anal. Chim. Acta 2004, 518, 1.

22. Rojas, F.; Ojeda, C.; Anal. Chim. Acta 2009, 635, 22.

23. Karpinska, J.; Talanta 2004, 64, 801. 